\title{
PENYULUHAN PEMILAHAN SAMPAH DOMESTIK SEBAGAI PENINGKATAN KESADARAN SISWA DALAM USAHA MENJAGA KUALITAS AIR WADUK JATIGEDE DI SMP NEGERI 2 DARMARAJA KABUPATEN SUMEDANG
}

\author{
Heti Herawati, Nia Kurniawati, Ine Maulina, Zahidah Hasan, Asep Sahidin, \\ Izza Mahdiana Apriliani, dan Lantun Paradhita Dewanti \\ Fakultas Perikanan dan Ilmu Kelautan, Unpad, Jatinangor, Indonesia \\ E-mail: h.herawati@unpad.ac.id
}

\begin{abstract}
ABSTRAK. Waduk Jatigede merupakan waduk yang terletak di Kabupaten Sumedang dengan membendung aliran Sungai Cimanuk. Tujuan pembangunan bendungan Jatigede diutamakan untuk peningkatan produksi padi dengan sistem jaringan irigasi rentang. Sampah menjadi permasalahan utama disetiap badan air baik itu sungai, danau maupun waduk. Jenis sampah yang masuk ke dalam perairan berbagai macam baik dari badan air itu sendiri ataupun dari sekitar badan air yang masuk. Pemahaman mengenai pemilahan sampah dan jenis-jenis sampah menjadi informasi yang belum banyak diketahui oleh masyarakat sekitar Waduk Jatigede. Informasi mengenai sampah tersebut yang dapat mencemari waduk dan mengganggu kualitas air waduk sehingga akan berpengaruh terhadap keanekaragaman jenis ikan dan keberlangsungan waduk dimasa yang akan datang juga belum banyak diketahui oleh warga masayarakat sekitar Waduk Jatigede. Dengan melihat berbagai persoalan tersebut di Waduk Jatigede, maka perlu dilakukan kegiatan penyuluhan mengenai bagaimana memilah dan mengelola sampah yang dihasilkan oleh rumah tangga agar tidak mencemari perairan Waduk Jatigede. Tujuan dari kegiatan ini yaitu memberikan pengetahuan dan keterampilan kepada usia remaja sebagai agen perubahan mengenai bagaimana mengolah sampah yang baik dan memberikan kesadaran secara lebih dini untuk ikut menjaga Waduk Jatigede. Metode penyuluhan yang digunakan adalah ceramah dan praktek langsung pada saat kegiatan berlamgsung. Berdasarkan penjelasan yang telah disampaikan dapat disimpulkan bahwa kegiatan penyuluhan ini dapat meningkatkan informasi mengenai pengelolaan sampah yang dihasilkan oleh rumah tangga dan lingkungan sekitar dan bagaimana agar tidak langsung masuk kedalam perairan Waduk Jatigede, sehingga dapat meningkatkan pemahaman dan wawasan peserta mengenai pentingya menjaga keberlangsungan kualitas air Waduk Jatigede.
\end{abstract}

Kata kunci: Waduk Jatigede; sampah; kualitas air

\section{DOMESTIC WASTE SELESCTION RELEASE AS INCREASING STUDENT AWARENESS TO MAINTAINING WATER QUALITY OF JATIGEDE RESERVOIR AT JUNIOR HIGH SCHOOL 2 DARMARAJA, SUMEDANG DISTRICT}

\begin{abstract}
Jatigede Reservoir located in Sumedang by stemming the flow of the Cimanuk River. The objective of the Jatigede dam is to increase rice production with a range of irrigation systems. Waste is the main problem in every water body, both rivers, lakes and reservoirs. Types of garbage that enter into various kinds of water either from the body of water itself or from around the body of water entering. An understanding of the sorting of waste and types of waste is information that has not been widely known by the community around the Jatigede Reservoir. Information about the waste that can contaminate reservoirs and disrupt the quality of reservoir water so that it will affect the diversity of fish species and the sustainability of reservoirs in the future is also not widely known by the community around the Jatigede Reservoir. By looking at these issues in the Jatigede Reservoir, extension activities need to be carried out on how to sort and manage the waste produced by households so as not to pollute the waters of the Jatigede Reservoir. The purpose of this activity is to provide knowledge and skills to adolescents as agents of change regarding how to process good waste and provide early awareness to take care of the Jatigede Reservoir. Based on the explanation that has been conveyed, it can be concluded that the extension activities can improve information about the management of waste produced by households and the surrounding environment and how to not directly enter the waters of the Jatigede Reservoir, so as to increase participants' understanding and insight regarding the importance of maintaining the water quality of the Jatigede Reservoir .
\end{abstract}

Key words: Jatigede reservoirs; garbage; water quality

\section{PENDAHULUAN}

Waduk Jatigede merupakan waduk yang terletak di Kabupaten Sumedang dengan membendung aliran Sungai Cimanuk. Tujuan pembangunan bendungan Jatigede diutamakan untuk peningkatan produksi padi dengan sistem jaringan irigasi rentang (BBWS 2009). Penggenangan Waduk Jatigede memberikan banyak pengaruh terutama dalam masuknya sampah yang berasal dari kegiatan disekitarnya. Sampah yang dihasilkan dari kegiatan rumah tangga sangat berpotensi menurunkan kondisi kualitas air waduk. Sampah menjadi permasalahn utama disetiap badan air baik itu sungai, danau maupun waduk. Jenis sampah yang masuk ke dalam perairan berbagai macam baik dari badan air itu sendiri ataupun dari sekitar badan air yang masuk. Limbah pabrik dan rumah tangga menjadi sampah yang paling banyak masuk ke dalam perairan juga waduk.

Pemahaman mengenai pemilahan sampah dan jenisjenis sampahmenjadi informasi yang belumbanyak diketahui oleh masyarakat sekitar Waduk Jatigede. Informasi mengenai sampah tersebut yang dapat mencemari waduk dan mengganggu kualitas air waduk sehingga akan berpengaruh terhadap keanekaragaman jenis ikan dan 
keberlangsungan waduk dimasa yang akan datang juga belum banyak diketahui oleh warga masayarakat sekitar Waduk Jatigede. Dengan melihat berbagai persoalan tersebut di Waduk Jatigede, maka perlu dilakukan kegiatan penyuluhan mengenai bagaimana memilah dan mengelola sampah yang dihasilkan oleh rumah tangga agar tidak mencemari perairan Waduk Jatigede yang diberikan di usia remaja berkisar antara 13-15 tahun atau siswa SMP.

Usia 13-15 atau siswa SMP masuk pada kelompok remaja awal yang merupakan peralihan dari masa anakanak ke masa dewasa yang mengalami perkembangan semua aspek/fungsi untuk memasuki masa dewasa. Di usia ini rasa ingin tahu yang tinggi harus didukung dengan informasi yang baik sehingga dapat menjadi pembiasaan. Salah satu informasi yang dibutuhkan oleh usia ini adalah mengenai pengelolaan sampah dan bagaimana dampak buruk yang dapat timbul apabila tidak dilakukan pengelolaan secara tepat. Oleh karena itu di usia ini dianggap sesuai untuk dapat diberikan penyuluhan mengenai pengelolaan sampah agar dapat menjadi pembiasaan untuk dapat terus dilakukan.

\section{METODE}

Metode yang digunakan dalam kegiatan PPM Integratif ini adalah dengan metode observasi, deskriptif dan partisipasi dengan pendekatan metode yang digunakan dalam kegiatan penyuluhan dan pelatihan yang bersifat 'persuasif-edukatif', yang dimaksudkan untuk memberikan pengetahuan, pemahaman, dan keterampilan dalam pengelolaan dan pengolahan sampah serta pentingnya menjaga kualitas air Waduk Jatigede. Pendekatan yang diterapkan dalam merealisasikan program PPM Integratif ini melalui metode participatory approach melalui upaya untuk merealisasikan program ini agar sesuai dengan tujuan dan outcome yang diharapkan (Widyasanti dkk, 2016). Pelaksanaan kegiatan PPM Integratif ini dilaksanakan pada tanggal 20 Agustus 2018 yang bertempat di SMP Negeri 2 Darmaraja Kabupaten Sumedang dihadiri oleh 28 orang peserta yang berasal dari siswa kelas VIII.

Khalayak sasaran dalam kegiatan PPM Integratif ini adalah para remaja yang berusia 13-15 tahun. Kelompok sasaran ini dianggap memerlukan informasi mengenai pengelolaan dan pengolahan dampah sebagai masyarakat yang terkena dampak pembangunan Waduk Jatigede sehingga dapat ikut menjaga kualitas air waduk. Dengan adanya kegiatan PPM Integratif ini diharapkan dapat meningkatkan kemampuan kelompok sasaran dalam pengetahuan mengenai pengelolaan dan pengolahan sampah dan diharapkan pula dapat menjadi agen perubahan dalam masyarakat untuk dapat menaga kualitas air Waduk Jatigede.

Kegiatan PPM Integratif ini dilakukan oleh narasumber yang memiliki kompetensi dalam mengelola dan mengolah sampah serta mampu memberikan informasi mengenai pentingnya menjaga kualitas air Waduk Jatigede. Adapun pokok bahasan yang disampaikan dalam kegiatan PPMP OKK ini antara lain:

1. Materi mengenai definisi sampah dan bagaimana klasifikasi sampah yang dihasilkan.

2. Cara menangani sampah, memilah sampah, jenis-jenis sampah

3. Pengelolaan dan pengolahan sampah.

4. Penjelasan mengenai pentingnya menjaga kualitas air Waduk Jatigede dan damapk yang ditimbulkan apabila terjadi penurunan kualitas air.

5. Evaluasi hasil penyuluhan.

Rancangan evaluasi yang dilaksanakan terhadap kegiatan pembinaan kepada masyarakat ini antara lain:

1. Evaluasi awal, yaitu pelaksanaan kegiatan survey lapangan untuk menentukan lokasi khalayak sasaran, penentuan dan kesepakatan peserta.

2. Evaluasi persiapan, yaitu pelaksanaan penentuan jadwal dan tempat kegiatan penyuluhan dan pelatihan serta persiapan instrumen.

3. Evaluasi proses, yaitu dengan pelaksanaan kegiatan ceramah, diskusi, simulasi.

4. Evaluasi hasil, yaitu pelaksanaan penilaian terhadap seluruh kegiatan yang telah diterima oleh peserta khalayak sasaran dengan tolak ukur atas kemampuan peserta untuk menerima materi yang telah disampaikan baik secara teoritis maupun secara teknis.

\section{HASIL DAN PEMBAHASAN}

Kegiatan penyuluhan merupakan salah satu upaya yang dilakukan untuk meningkatkan wawasan peserta dalam hal ini siswa SMP Negeri 2 Darmaraja mengenai pengelolaan sampah dan menjaga kualitas air Waduk Jatigede. Penyuluhan yang dilakukan dihadiri oleh 32 orang yang merupakan perwakilan dari dari berbagai tingkat siswa baik kelas 7, 8 dan 9 juga dihadiri oleh 2 orang guru kelas. Kegiatan dilaksanakan di ruang kelas SMP Negeri 2 Darmaraja.

Kegiatan ini berisi materi mengenai pengertian sampah, jenis-jenis sampah, pemilahan dan pengolahan sampah serta bagaimana cara menjaga kondisi kualitas air Waduk Jatigede. Materi diberikan selama 45 menit kemudian dilanjukan dengan kegiatan tanya jawab dengan peserta. Melalui kegiatan tanya jawab ini dapat dilihat antusiasme peserta yang cukup tinggi mengenai materi yang diberikan.

Sampah-sampah yang dihasilkan disekitar sekolah terdiri dari berbagai jenis yang didominasi oleh sampah plastik dari jajanan yang terdapat disekitar sekolah. Seperti diketahui jenis sampah plastik ini merupakan sampah yang sulit untuk diuraikan oleh alam. Sifat-sifat bahan plastik inilah yang membuatnya sulit tergantikan dengan bahan lainnya untuk berbagai aplikasi khususnya dalam 
kehidupan sehari-hari mulai dari kemasan makanan, alat-alat rumah tangga, mainan anak, elektronik sampai dengan komponen otomotif. Peningkatan penggunaan bahan plastik ini mengakibatkan peningkatan produksi sampah plastik dari tahun ke tahun. Sebagai gambaran konsumsi plastik di Indonesia mencapai $10 \mathrm{~kg}$ perkapita pertahun, sehingga dapat diprediksikan sebesar itulah sampah plastik yang dihasilkan (Ginting, 2010).

Plastik sangat sulit terurai dalam tanah, membutuhkan waktu bertahun-tahun dan ini akan menimbulkan permasalahan tersendiri dalam penanganannya. Pembuangan di Tempat Pembuangan Akhir (TPA) sampah bukanlah solusi yang cukup bijak dalam pengelolaan sampah plastik ini. Peranan para pemulung dalam mengurangi timbunan sampah plastik patut mendapat apresiasi meskipun ini tidak bisa menghilangkan seratus persen sampah plastik yang ada. Perlu adanya manajemen sampah plastik mulai dari lingkungan terkecil yaitu rumah tangga hingga skala besar meliputi kawasan kota yang dikelola oleh pemerintah kota atau daerah setempat. Untuk memudahkan pengelolaan sampah plastik pada skala rumah tangga, maka perlu adanya pemahaman tentang jenis-jenis plastik, kandungan materialnya, hingga dampaknya terhadap lingkungan sehingga diharapkan terbentuk manajemen pengelolaan yang tepat.

Mengingat kandungan energi yang tinggi dari bahan plastik, maka potensi pemanfaatannya sebagai salah satu sumber energi memiliki prospek yang cukup bagus di masa mendatang. Dari sini bisa didapatkan dua keuntungan sekaligus yaitu mengurangi problem sampah dan juga menghasilkan energi yang bisa digunakan untuk mengurangi ketergantungan pada sumber energi konvensional (Asmadi dan Suharno 2012). Beberapa teknologi bisa digunakan untuk mengkonversi sampah plastik menjadi bahan bakar diantaranya yang sampaikan pada saat penyuluhan adalah:

1. konversi ke bahan bakar padat (dilakukan dengan mencacah sampah plastik dan kemudian membriketnya untuk nantinya menjadi bahan bakar briket. Bahan bakar ini kemudian bisa digunakan untuk pembakaran di tungku-tungku industry),

2. Konversi ke bahan bakar cair (dengan menggunakan prinsip pirolisis dimana sampah plastik dipanaskan pada suhu sekitar $500^{\circ} \mathrm{C}$ sehingga fasenya akan berubah menjadi gas dan kemudian akan terjadi proses perengkahan (cracking). Setelah itu didinginkan kembali dan bisa mendapatkan bahan bakar cair setara dengan bensin dan solar.

Sampah plastik memberikan dampak yang negative sangat luar biasa bagi manusia dan lingkungan. Sampah plastik juga akan memberikan dampak negative terhadap perubahan lingkungan baik disekitar waduk maupun di dalam waduk itu tersebut. Salah satu dampak yang ditimbulkan dan dapat menjadi permasalahan besar adalah menurunnya kualitas air waduk yang dapat menurunkan pula manfaat dan kegunaan waduk sebagai sumber air dan tempat dilakukan kegiatan perikanan (Effendi 2003). Dapat diuraikan dampak yang ditimbulkan apabila terjadi penurunan kualitas air waduk adalah sebagai berikut:

1. Mengganggu rantai makanan

2. Pencemaran air tanah

3. Menurunkan keanekaragaman sumberdaya hayati

4. Terjadi peningkatan kandungan logam berat

5. Menurunkan kegiatan pariwisata

6. Hilangnya habitat berbagai organisme

Hasil kegiatan PPM Integratif ini secara garis besar mencakup beberapa komponen sebagai berikut:

1. Keberhasilan target jumlah peserta pelatihan

2. Ketercapaian tujuan pelatihan

3. Ketercapaian target materi yang telah direncanakan

4. Kemampuan peserta dalam penguasaan materi

Target peserta pelatihan seperti direncanakan sebelumnya adalah remaja usia 13-15 tahun yang dianggap usia paling tepat dapat diberikan penyuluhan, kegiatan ini diikuti oleh 38 orang peserta. Dengan demikian dapat dikatakan bahwa target peserta tercapai lebih dari 100\%. Angka tersebut menunjukkan bahwa kegiatan PPM Integratif dilihat dari jumlah peserta yang mengikuti dapat dikatakan berhasil/ sukses.

Ketercapaian tujuan penyuluhan secara umum sudah baik, namun keterbatasan waktu yang disediakan mengakibatkan tidak semua materi dapat disampaikan secara detil. Namun dilihat dari hasil latihan para peserta yaitu sangat antusias dan bersemangat, maka dapat disimpulkan bahwa tujuan kegiatan ini dapat tercapai. Ketercapaian target materi pada kegiatan PPM Integratif ini cukup baik, karena materi pendampingan telah dapat disampaikan secara keseluruhan.

Faktor-faktor yang menjadi kendala dalam kegiatan ini tidak ada karena ternyata faktor-faktor yang merupakan pendukung/positif lebih banyak dirasakan dalam kegiatan penyuluhan ini. Beberapa hal yang merupakan faktor pendukung, antara lain: sasaran sebagai mitra kerja yang sesuai kebutuhan dan karakteristiknya dan rasa antusiasme yang ditunjukkan dengan banyaknya pertanyaan diberikan selama kegiatan penyuluhan ini berlangsung. Karena itu kegiatan ini mengisyaratkan untuk senantiasa dilakukan secara periodik, sistematis, dan berkesinambungan.

\section{SIMPULAN}

Program PPM Integrasi yang ditujukan kepada para siswa SMP Negeri 2 Darmaraja Kabupaten Sumedang mengenai Pengelolaan Sampah dan Pentingnya Menjaga Kualitas Air Waduk Jatigede sebagai upaya meningkatkan kesadaran akan penting-nya menjaga kebersihan lingkungan dari sampah-sampah yang dihasilkan dan tidak membuangnya secara langsung kedalam waduk, diharapkan dapat membantu meningkatkan kondisi dan 
pola hidup yang lebih sehat, bagi para siswa dan guruguru di sekitar. Selain itu kurangnya informasi mengenai bagaimana mengelola sampah terutama sampah plastik juga masih banyak ditemukan di sisa-siswa SMP Negeri 2 Darmaraja tersebut, oleh karena itu pemberian penyuluhan ini sangat tepat.

\section{UCAPAN TERIMA KASIH}

Penulis mengucapkan terima kasih kepada Direktorat Riset, Pengabdian Pada Masyarakat dan Inovasi Universitas Padjadjaran yang telah memberikan dana hibah Pengabdian Pada Masyarakat Integrasi Riset, ucapan terima kasih disampaikan kepada Kepala Sekolah dan Guru-guru di SMP Negeri 2 Darmaraja Kabupaten Sumedang sehingga program pengabdian ini dapat terlaksana dengan baik.

\section{DAFTAR PUSTAKA}

Asmadi dan Suharno.,2012. Dasar - Dasar Teknologi Pengolahan Air Limbah. Gosyen Publishing. Yogyakarta
Balai Besar Wilayah Sungai Cimanuk-Cisanggarung (BBWS). 2009. Profil BBWS Sungai CimanukCisanggarung. Direktorat Jenderal Sumber Daya Air. Departemen Pekerjaan Umum. Sumedang.

Effendi, H. 2003. Telaah Kualitas Air. Kanisius, Yogyakarta.

Fitriani, S. I. 2013. Proyek Bendungan Jatigede Sumedang. Institut Teknologi Bandung. Bandung.

Fordian, D., Hana, A. L., Rendra, R., dan Esa, A. A. Penyuluhan Metode Pembuangan Sampah Organik dan Sampah Anorganik Bagi Rymah Tangga di Lingkungan (Studi Kasus di RW 03 Desa Cisempur Kec. Jatinangor). Dharmakarya: Vol 6 (3). 129-135.

Ginting, P., 2010. Sistem Pengolahan Lingkungan Dan Limbah Industri. Yrama Widya. Bandung

Widyasanti, A., Putri, S.H. dan Dwiratna S.N.P. 2016. Upaya Pemberdayaan Masyarakat Melalui Pelatihan Pembuatan Produk Sabun Berbasis Komoditas Lokal di Kecamatan Sumakamantri Ciamis. Dharmakarya: Vol 5 (1). 29-33. 